\title{
A DISCUSSION OF THE PHENA OF PERILYPUS ORNATICOLLIS (LECONTE) (COLEOPTERA: CLERIDAE), WITH A REVIEW OF SUBSPECIES TAXA IN THE FAMILY CLERIDAE
}

\author{
By Jonathan R. MaWdsLey \\ Department of Entomology \\ Museum of Comparative Zoology \\ Harvard University \\ Cambridge, MA 02138 USA
}

\section{INTRODUCTION}

Ginter Ekis's 1977 monograph of the genus Perilypus Spinola provides an excellent account of the species of this genus. However, material of Perilypus ornaticollis (LeConte) from the State of Mexico was not available to Ekis for study. Ekis recognized two phena in this species on the basis of differences in pronotal and elytral coloration: one phenon distributed from northern Ohio to Louisiana; the other ranging from Louisiana to the northern Gulf coast of Mexico. The author has suggested elsewhere that these interpopulational differences in coloration are probably maintained by participation in two different mimicry rings by adult Perilypus ornaticollis (Mawdsley 1992:28).

Recently, the author was given an unusual female specimen of Perilypus ornaticollis collected by Gabriela Chavarria Villaseñor near Jalatlaco, Mexico (supported by a Putnam Expedition Grant from the Museum of Comparative Zoology). The pronotum of this specimen differs in its coloration from that of all other specimens of this species examined by Ekis (1977:107), while the coloration of the elytra of this specimen differs from that of all previously known specimens of this species from Mexico but resembles that of specimens from the northern portion of this species' range. This specimen is also considerably larger than all other specimens of Perilypus ornaticollis (LeConte) examined by Ekis (1977: 105-107) and the author. The maximum length for females of Perilypus ornaticollis (LeConte) reported by Ekis (1977:105) is

Manuscript received 13 October 1992. 
$8.4 \mathrm{~mm}$, while the specimen which I have been given measures $10.1 \mathrm{~mm}$ in overall length. Because of these morphological differences and because of this specimen's unique collecting locality, I have decided to provide a description and illustration of this specimen, which in my opinion represents a previously unrecognized phenon of this species. For practical reasons explained below, I prefer to call this the "trimaculate phenon." I have seen no evidence that individuals of this phenon are mimetic; however, the coloration pattern of the one specimen available is similar to that of members of the family Cantharidae.

The subspecific groups designated as "phena" by Ekis in the genus Perilypus correspond to those designated as "subspecies" by other clerid workers. The author does not think it advisable to formally designate subspecific taxa in the family Cleridae, particularly in the absence of detailed studies of population genetics, reproductive isolation, and speciation in this family. Such formal designations imply a stability at the subspecific level which, in phenotypically plastic groups such as the Cleridae, may not exist. I also doubt the validity of subspecific taxa in a strictly monophyletic system of classification. Rather, I advocate the use of informal terms such as "morph" and "phenon" to designate variant forms within a species. An annotated historical review of the application of subspecies taxa in the family Cleridae is provided below.

\section{Perilypus ornaticollis (LeConte)}

Trimaculate phenon

Description:

Length: from ocular notch to elytral apices $10.1 \mathrm{~mm}$

Structural morphology: As described by Ekis (1977:105-107).

Coloration: Head, legs, elytra, and abdomen dark brownish-black. Pronotum yellow, with three brownish-black maculae on disc: two arcuate maculae, one on either side of the midline, extending from the pronotal collar across the pronotum proper and terminating at the apex of the pronotal arch; one small triangular basomedial macula.

Diagnosis: Specimens of this phenon will run to Perilypus ornaticollis in Ekis's key (Ekis 1977:23-26) on the basis of their brownish-black legs. However for the sake of clarity, the first 
clause of couplet 11 in Ekis's key should be changed from "Pronotal disc vitta furcate" (Ekis 1977:23) to read "Pronotal disc either trimaculate or with a furcate vitta."

Illustration: See Figure 1 for a habitus drawing of the head, pronotum, and elytra of the specimen described above.

Material: One specimen, female, collected while sweeping, 13 June 1992, km 15.5 Carretera México-Jalatlaco, Estado de México, México, legit Gabriela Chavarria Villaseñor, in collection of MCZ.

The additional material of Perilypus ornaticollis (LeConte) examined during the course of this study has already been

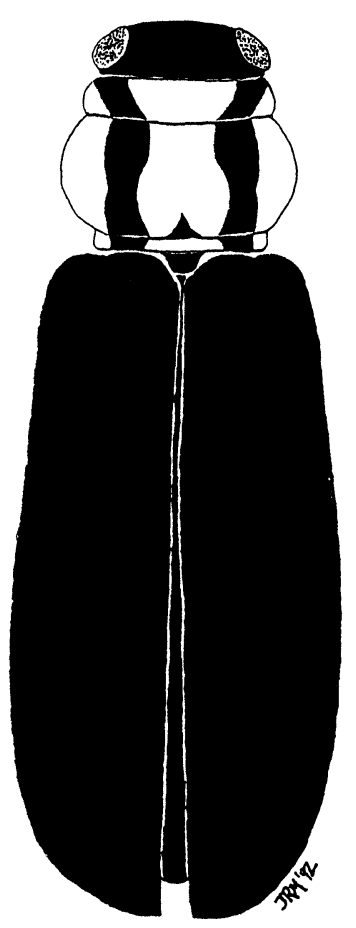

Figure 1: Perilypus ornaticollis (LeConte), trimaculate phenon. Length of specimen shown $10.1 \mathrm{~mm}$. 
described by Ekis (1977:107): 1 female, HOLOTYPE, "Ohio" (ex MCZC); 3 females, Esperanza Ranch, Brownsville, Texas (1 ex BMNH, 2 ex MCZC); 1 female, San Rafael, Jicaltepec, Estado de Veracruz, Mexico (ex MCZC).

\section{An Annotated Historical Review of Subspecies Taxa in the Family Cleridae}

Very few subspecies have been proposed in the family Cleridae (see Corporaal 1950). A considerable number of varietal names have been proposed, primarily for the African and European faunas, but these will not be treated here. The most active clerid workers during the past century have been those in North America, and it is in the North American fauna that the greatest number of subspecies have been proposed.

The first author to apply the category of subspecies to a taxon in the family Cleridae was Barr (1947:21-22), who described Enoclerus eximius trullionis from the Great Basin region of the western United States. Further investigations on the part of Barr $(1950: 61 ; 1962: 108)$ have shown this to be an ecologically and morphologically distinct species which had already been described by A. B. Wolcott under the name Enoclerus acerbus.

It is perhaps not surprising that a large number of proposed subspecies in the family Cleridae are in the genus Enoclerus Gahan (see the discussion of Barr 1976 below). Species of this genus are brightly colored and popular with collectors; they are also very variable in coloration. Until such time as this genus can be reviewed in its entirety and adequate, representative samples of all species accompanied by pertinent biological and ecological data are available for study, it appears to me to be pointless to continue to describe taxa such as subspecies in this genus.

Winkler (1959:71-75) described a new subspecies of Trichodes crabroniformis Fabricius (Trichodes crabroniformis hidalgo) on the basis of a single specimen from Spain. The characters given by Winkler in his diagnosis of this subspecies seem to apply equally well to specimens of the "nominate subspecies" from Greece in the collection of the author. This leaves, of course, the considerable geographic gap between Spain and Greece as the only justification for the continued recognition of this "subspecies." However, the dangers of founding subspecies solely on geographical distribution 
are well-known (see Lane 1974:531). Furthermore, species with discontinuous distributions are not unknown in the family Cleridae; a particularly good example is the east African species Aphelochroa sanguinalis (Westwood). It is also possible that Winkler's specimen represents a recent introduction or that the specimen was simply mislabelled.

The next two applications of subspecies taxa to members of the family Cleridae were also in the genus Trichodes Herbst: those of Zimmermann $(1971 ; 1973)$ and that of Foster (1976). Both of these works follow in a long tradition (primarily European) of describing as "subspecies" what are merely geographic variants whose level of reproductive isolation and genetic differentiation has not been ascertained. Despite the enormous wealth of material of the genus Trichodes available for study, nothing is known about the mechanisms of reproductive isolation or speciation in this genus. Most subspecies taxa should be treated as phena and the subspecific epithets suppressed until further research into speciation in this genus can be conducted. Unlike many species of Cleridae, species of the genus Trichodes can be reared in the laboratory (Foster 1976:5-6), making captive breeding experiments to determine degrees of reproductive isolation feasible. Such experiments could also be directed towards ascertaining the extent of genetic (as opposed to environmental) determination of coloration in this genus, as the taxonomy of the genus Trichodes is almost exclusively based on characters of coloration.

Barr (1976) described six subspecies, all in the genus Enoclerus. Two of these belong to the species Enoclerus coccineus (Schenkling) and in the author's opinion should be treated as phena; I can find no distinction other than coloration between them. The remaining subspecies belong to Enoclerus laetus (Klug); at the present, these should be recognized as phena, but after further study involving breeding experiments several of them may merit recognition as separate species.

Winkler and Zirovnicky (1978) described Trichodes israelicus turcicus from Turkey on the basis of a single specimen. Their paper was originally written to clarify taxonomic confusion in the Turkish species of the genus Trichodes but has only made matters worse. It is extremely premature to describe a new subspecies from a single specimen when the nominate subspecies is itself only 
known from a single specimen. An adequate survey of interspecific variation is impossible based on such limited material. Furthermore, Trichodes israelicus Winkler is evidently a synonym of Trichodes ganglbaueri Escherich; I find Winkler and Zirovnicky's argument (1978:480-482) that the type of Trichodes ganglbaueri was somehow mislabelled to be completely unsupported and very unconvincing. Indeed, one must wonder about the validity of the work of authors who claim "Scientifical [sic] importance of the supposed type specimen is very little if it is discordant with [the published] description" (Winkler and Zirovnicky 1978:481). Most clerid workers realize that published descriptions and even illustrations, particularly those of older authors, are inadequate for recognition of clerid taxa and must therefore rely on the preserved type specimens when forming their conception of taxa (see Ekis 1975 for an extensive discussion of the differences between clerid taxa described and illustrated by M. Spinola and the type specimens on which these taxa were based).

As noted above, Ekis (1977), in revising the genus Perilypus, did not use the category of subspecies but rather referred to geographically distinct populations as "phena" in the absence of data about reproductive isolation and mechanisms of speciation. Many of the subspecific units described as phena by Ekis would have been given subspecific epithets by other clerid workers on the basis of slight morphological differences, chiefly those of coloration. In the author's opinion, it is best to follow Ekis and refer to such populations or groups of populations as phena, since morphological differences can arise between populations of a species through the action of any of a number of agents without interruption of gene flow. Such morphological differences are often quite pronounced, particularly in families such as the Cleridae whose species exhibit a high degree of phenotypic plasticity.

As a final note, I would caution against the hasty description of formal subspecific taxa, particularly "varieties" and "aberrations" but also "subspecies," which has unfortunately formed a considerable part of clerid systematics in the past. While resorting to such informal terms as "morph" and "phenon" (as defined by Ekis 1977:5-6) means that workers will have their names after fewer taxa, in the end a much clearer picture of the present-day state of the family Cleridae will emerge. 


\section{SUMMARY}

The phena of Perilypus ornaticollis (LeConte) are discussed in reference to an unusual specimen from Mexico. The subspecific groups informally designated as "phena" by Ekis (1977) correspond with those formally designated as "subspecies" by other clerid workers. An annotated historical review of subspecies taxa in the family Cleridae is provided. In the opinion of the author, workers should refrain from formally designating subspecific taxa in the family Cleridae in the absence of adequate information about clerid distribution, population genetics and speciation.

\section{LITERATURE CITED}

BARR, W. F.

1947. A New Subspecies of Enoclerus from the Great Basin Region of the Western United States (Coleoptera: Cleridae). The Great Basin Naturalist. 7: 21-22.

1950. Systematics and Synonymical Notes on New World Clerid Beetles (Coleoptera). Entomologische Berichten. 13: 61-62.

1962. Family Cleridae. pp. 105-112 in The Beetles of the Pacific Northwest, Volume 3. M. Hatch, ed. Seattle, University of Washington Press. 503 pp.

1976. Descriptions of Taxonomic Notes of Enoclerus and Some Allied Genera. Melanderia. 24: 18-35.

CORPORAAL, J. B.

1950. Coleopterorum Catalogus, Supplementa Pars 23, Editio Secunda, Cleridae. W. Junk, The Hague. 373 pp.

EKIS, G.

1975. Taxonomic and nomenclatural status of clerid taxa described by Massimiliano Spinola (1780-1857) (Coleoptera: Cleridae). Bollettino del Museo di Zoologia dell'Universita di Torino. 1: 1-80.

1977. Classification, Phylogeny, and Zoogeography of the Genus Perilypus (Coleoptera: Cleridae). Smithsonian Contributions to Zoology. 227: i-iv + 1-138.

FOSTER, D.

1976. Revision of North American Trichodes (Herbst) (Coleoptera: Cleridae). Special Publications of the Museum of Texas Tech University. 11: 3-86.

LANE, F.

1973. A Few Remarks on Dr. Lawrence S. Dillon's Revision of the Genus Lagocheirus (Coleoptera: Cerambycidae). Studia Entomologica. 16: 529-533.

MAWDSLEY, J. R.

1992. A Large Coleopteran Mimicry Ring from Eastern North America. Young Entomologists' Society Quarterly. 9: 3: 25-38. 
WINKLER, J. R.

1959. Trichodes crabroniformis hidalgo, nueva subespecie de Clerido de Espana. Graellsia. 17: 71-75.

WINKLER, J. R. AND J. ZIROVNICKY

1978. Trichodes Herbst 1792, Series leucopsideus, A Revision of PonticMediterranean Group of Species (Coleoptera: Cleridae). Acta Universitatis Carolinae Biologica. 1978: 457-484.

ZimmermanN, S.

1971. Ergebnisse Zoologischer Sammelreisen in der Turkei, Gattung Trichodes Herbst. Annals du Naturhistorischer Museum de Wien. 75: 591-625.

1973. Nachtrag zu Ergebnisse zoologischer Sammelreisen in der Turkei, Gattung Trichodes Herbst (Cleridae, Coleoptera). Annals du Naturhistorischer Museum de Wien. 77: 409-419. 

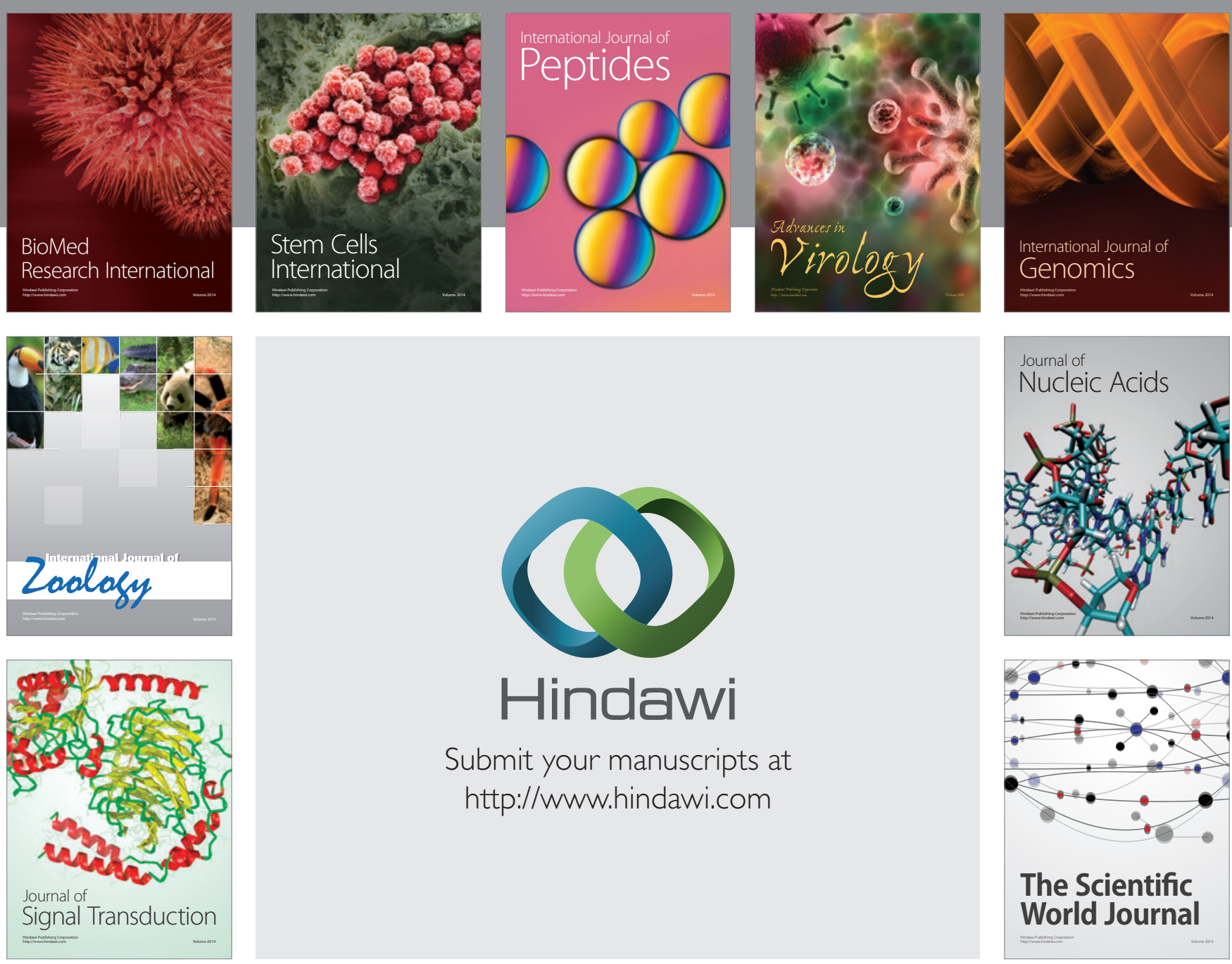

Submit your manuscripts at

http://www.hindawi.com
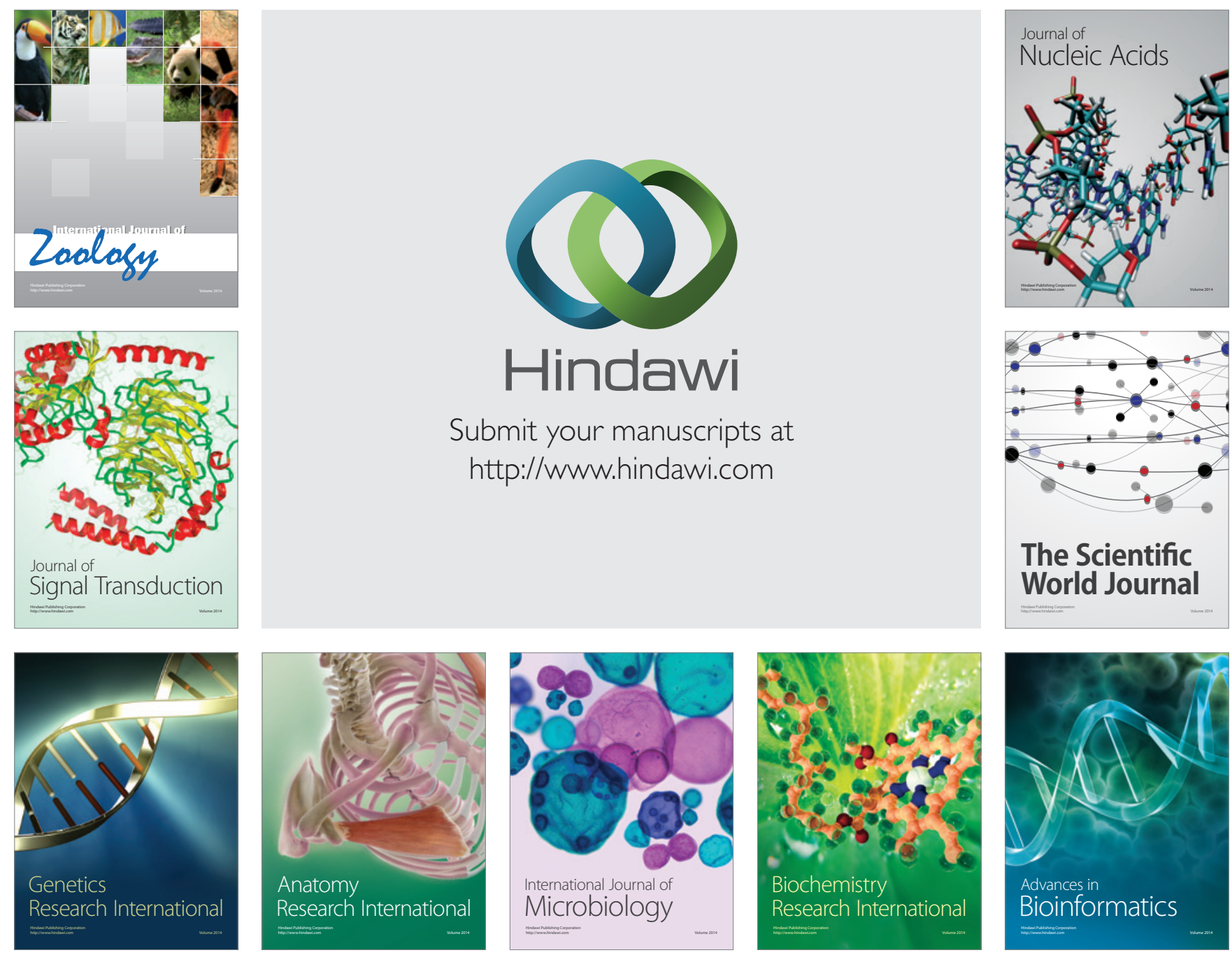

The Scientific World Journal
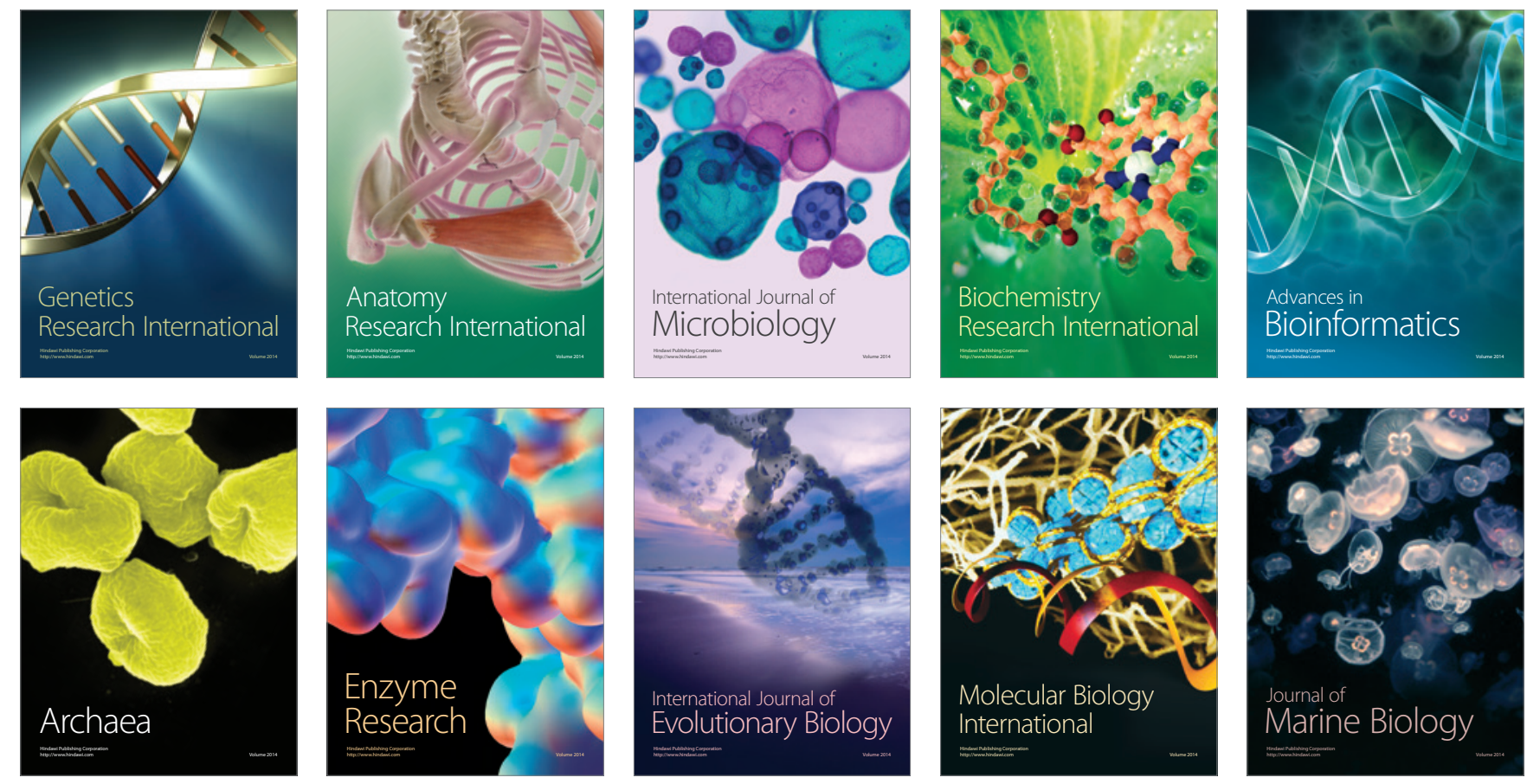